\title{
Does routine child health surveillance contribute to the early detection of children with pervasive developmental disorders? - An epidemiological study in Kent, U.K. Marc Tebruegge*, Vridhagiri Nandini and Jane Ritchie
}

\author{
Address: Department of Community Paediatrics, Maidstone Weald Primary Care NHS Trust, Preston Hall Hospital, Maidstone, Kent ME20 7NJ, \\ United Kingdom \\ Email: Marc Tebruegge* - MARC.TEBRUGGE@lshtm.ac.uk; Vridhagiri Nandini - nandinivgiri@yahoo.co.uk; \\ Jane Ritchie - JANE.RITCHIE@Ishtm.ac.uk \\ * Corresponding author
}

Published: 03 March 2004

BMC Pediatrics 2004, 4:4

This article is available from: http://www.biomedcentral.com/I47I-243I/4/4

(C) 2004 Tebruegge et al; licensee BioMed Central Ltd. This is an Open Access article: verbatim copying and redistribution of this article are permitted in all media for any purpose, provided this notice is preserved along with the article's original URL.

\begin{abstract}
Background: Recently changed guidelines for child health surveillance in the United Kingdom (U.K.) suggest targeted checks only, instead of the previously conducted routine or universal screening at 2 years and 3.5 years. There are concerns that these changes could lead to a delay in the detection of children with autism and other pervasive developmental disorders (PDD). Recent U.K. studies have suggested that the prevalence of PDD is much higher than previously estimated. This study establishes to which extent the routine checks contributed to the early detection and assessment of cases of PDD. Simultaneously we have evaluated the process involved and estimate the prevalence of PDD in our district.

Methods: Retrospective study design utilising community medical files. Headteachers of schools $(n=75)$ within Maidstone district (Kent) were asked to report all children with an established diagnosis of autism or PDD attending year 4 (born ' 91 and ' $92 / n=2536$ ) in October 2000 based on educational records.

Results: 59 schools (78.7\%) took part in the study. A total of 33 children were reported. 2 I fulfilled the inclusion criteria ( 12 falsely reported). The prevalences were (per 10,000): PDD 82.8 (male to female ratio 6:I), childhood autism 23.7, Asperger's syndrome II.8 and autistic spectrum disorder 47.3. Co-existing medical conditions were noted in $14.3 \%$; $52.4 \%$ were attending mainstream schools. In $63.2 \%$ of cases concerns - mainly in the area of speech and language development (SLD) - had been documented at the 2 year check. At the 3.5 year check concerns were noted in $94.1 \%$ - the main area was again SLD (76.5\%), although behavioural abnormalities were becoming more frequent (47.I\%). A total of I 3 children $(68.4 \%)$ were referred for further assessment as a direct result of the checks.

Conclusions: The prevalences for different types of PDD were similar to figures published recently, but much higher than reported a few years ago. Analysis of our data suggests that routine surveillance is a valuable contributing factor for the early detection of PDD and thereby facilitates early intervention. Thus, if routine surveillance ceases, then an alternative method of early detection should be put in place.
\end{abstract}




\section{Background}

Autism and other pervasive developmental disorders (PDD) continue to be an area of major public concern, especially in the light of recent debates about possible links between the MMR vaccine and these conditions. An increasing number of publications have since demonstrated that there is no association between the vaccine and the development of autism or PDD [1-3].

Since 1966, when the first epidemiological survey of autistic conditions in England was published by Lotter [4], several studies have been performed worldwide. However, there has been little epidemiological data available in the last decade regarding the United Kingdom until Chakrabarti and Fombonne [5] published a survey conducted amongst pre-school children. The authors found that the rates of PDD were considerably higher in their population than in previous reports.

Routine Child Health Surveillance - which includes a 2year and a 3.5-year check - used to be an important screening tool for the paediatric population in the United Kingdom. The assessments, which were carried out by a health professional, consisted of testing and enquiring about vision, hearing, motor development, speech development and behavioural aspects. The latter two areas are particularly of relevance in the detection of PDD.

In recent years many Community Child Health Departments have ceased to carry out routine 2-year and 3.5-year developmental surveillance checks. Instead of the universal screening of the entire population, targeted or selective screening has been introduced in many areas. Some health care trusts have been forced to adopt these policies earlier because of financial constraints and shortage of staff.

There have been concerns about the possibility that this change could consequently lead to a later detection of cases of PDD, especially at the "milder end" of autistic spectrum disorders. Early detection of these children and intervention is essential, since this can lead to considerable improvement in outcome as previously demonstrated by various authors [6-8].

In this study we tried to assess to what extent the 2- and 3.5 -year check (in a period when these checks were routinely carried out) contributed to the early detection of PDD. Simultaneously we intended to estimate the prevalence of the different types of PDD in our area and evaluate the process which has led to the diagnosis of these cases. Another aim was to obtain more detailed information about these patients, such as gender distribution, coexisting medical conditions, therapeutic interventions and schooling.

\section{Methods}

This retrospective study was conducted on a paediatric population in Maidstone district (Kent, U.K.). The area comprises of a mixture of urban, rural and semi-industrial areas. The total population living in this area was 220.239 in June 2000 ( $49.0 \%$ male, 51.0\% female). The majority of the population was of British Caucasian origin, with a relatively small proportion of immigrants and foreigners of $1.4 \%$, predominately of Indian $(\mathrm{n}=763)$ and AfroCarribean $(n=592)$ origin. The social class distribution based on occupation was as follows: I $4.8 \%$, II $32.5 \%$, III manual $19.7 \%$, III non-manual $24.5 \%$, IV $13.2 \%$ and V $5.4 \%$.

We included all school children who were attending year 4 in the 75 schools (born in 1991-1992, aged 8-9 years) within in the catchment area of the Maidstone district on the $1^{\text {st }}$ of October 2000. Since many features of PDD become more pronounced with increasing age we decided to concentrate on this particular age group of children. By that age the majority of children with significant autistic difficulties are likely to have presented. The total number of children included in the survey was 2,536.

Headteachers and Special Educational Needs Coordinators of all primary schools were informed about this study by written correspondence. They were asked to provide a list - based on their educational records - of all children attending their school who were believed to have a definite or established diagnosis of any of the following disorders: autism, autistic spectrum disorder, Asperger's syndrome, semantic pragmatic language disorder, pervasive developmental disorder or atypical autism.

The next step was to obtain the community medical files of all children reported by the schools. These files contain information about child health surveillance assessments, medical problems and treatment, developmental assessments, therapy reports and the statements for special educational needs. The files were systematically reviewed by two of the authors (V.N. and M.T.) to obtain information about the diagnosis, age at diagnosis and which type of professional had made the diagnosis. The diagnostic validity was checked by matching symptoms documented in the notes against ICD-10 criteria. Each of the two authors reviewed the notes independently and assigned the child to one of the 3 categories outlined below.

We focused on the pre-school health surveillance checks performed at 2 years and 3.5 years to assess if and which concerns had been documented and whether they had been acted upon. The initial referral was considered to be the direct result of a routine check if the referral was made within 4 weeks following the check. 
Further details which we included were therapeutic interventions, additional assistance at school, whether the child was statemented for special educational needs and whether the child was attending a mainstream-school or a specialised school.

For the purpose of this study we have chosen to divide our patients with pervasive developmental disorder (PDD) into three groups: childhood autism, Asperger's syndrome and autistic spectrum disorder. In this paper we are using the term childhood autism according to ICD-10 criteria to describe children who have been referred to as "infantile autism", "autistic disorder" or "autistic syndrome" by other authors. Asperger's syndrome was defined by using ICD-10 criteria and the widely used criteria published by Gillberg and Gillberg [9]. The term autistic spectrum disorder is used to describe a collection of all other pervasive developmental disorders not fulfilling the criteria of the other two categories, including atypical autism and semantic pragmatic language disorder (ICD-10 categories F 84.1, F 84.8 and F 84.9).

\section{Results}

Out of 75 schools within the Maidstone district 59 $(78.7 \%)$ responded. The other 16 schools $(21.3 \%)$ did not participate in the study, despite repeated correspondence and assurance that they would not be breaching confidentiality as this was a survey of known medical details and no family would be contacted. All schools for children with special needs including the unit for the hearing impaired took part in the study. The total number of children attending year 4 within our area at the time when the study was undertaken was 2,536 .

The total number of children reported was 33 . The community medical files of all these children were obtained and independently reviewed by the authors as described above. The concordance between reviewers regarding assignment of cases to a particular diagnostic category or exclusion from the study (i.e. falsely reported case) was $100 \%$.

Table I: Diagnosis in the group of falsely reported children

\begin{tabular}{lc}
\hline Diagnosis / condition & Number of children \\
\hline ADHD & 3 \\
cerebral palsy & 2 \\
Dyspraxia & 2 \\
Epilepsy & 1 \\
learning difficulties & 3 \\
sensorineural hearing loss & $\mathrm{I}$ \\
speech and language delay & 4
\end{tabular}

Table I shows the spectrum of diagnosis in children not fulfilling inclusion criteria $(n=12)$, who were falsely reported by the participating schools. Four children had more than one diagnosis.
We found that 21 of these children had been diagnosed with a type of pervasive developmental disorder, but 12 children did not have a diagnosis of PDD and thus had been reported falsely. The most common diagnosis in the latter group were speech and language delay, ADHD (attention deficit hyperactivity disorder) and moderate learning difficulties. Some children had more than one diagnosis (see table 1). The false reports came from 5 different schools.

Out of the 21 children (total prevalence of PDD 82.8 per 10.000 ) who fitted the inclusion criteria 6 had a diagnosis of childhood autism (prevalence 23.7 per 10.000), 3 had Asperger's syndrome (prevalence 11.8 per 10.000) and 12 had autistic spectrum disorder (prevalence 47.3 per 10.000). The male:female ratio for the whole group was 6:1. All children diagnosed with childhood autism were male.

The mean age at diagnosis for the whole group was 4.99 years (range $2.75-9.42$ years, median 4.42 years). The mean age at diagnosis varied considerably between the subgroups (see table 2). The subgroup of children with childhood autism had the lowest mean age at diagnosis (mean 3.13 years, range $2.75-3.50$ ). All children in this subgroup had symptoms before 36 months of age.

In 14 patients $(66.7 \%)$ the diagnosis was established at pre-school age, 7 (33.3\%) were diagnosed after entering school ( $>5.0$ years of age).

The majority of children $(\mathrm{n}=14 / 66.7 \%)$ were assessed and diagnosed by Consultant Community Paediatricians. In three cases the diagnosis was made by experienced Community Child Health doctors. One child with Asperger's syndrome was diagnosed by a Consultant Psychiatrist and another child with atypical autism by a multidisciplinary team at a tertiary referral centre. Two children with semantic pragmatic language disorder were diagnosed by Speech and Language Therapists.

All 14 children diagnosed by the Consultant Community Paediatricians were also regularly followed up by them or the school health service. One patient with Asperger's syndrome was followed up by the Child and Adolescent Mental Health Service. All 21 children who were included into the study had previously been assessed and treated by the Speech and Language Therapy team, most of them continued to be seen by that department.

Coexisting conditions were documented in 10 children $(47.6 \%)$. The most common condition was ADHD, present in 5 children $(23.8 \%)$. One patient $(4.8 \%)$ was diagnosed with dyspraxia and one with dyslexia. Two 
Table 2: Mean age at diagnosis

\begin{tabular}{lccc}
\hline Diagnosis & Number of patients & Mean age at diagnosis & Range (years) \\
\hline Childhood autism & 6 & 3.13 & $2.75-3.50$ \\
Asperger's syndrome & 3 & 7.22 & $5.75-9.25$ \\
Autistic spectrum disorder & 12 & 5.37 & $3.33-9.42$ \\
\hline
\end{tabular}

Table 2 shows the mean age at diagnosis and the range of age at which the diagnosis was made according to diagnostic subgroups.

patients $(9.5 \%)$ were suffering from epilepsy and one had hydrocephalus.

Eleven children $(52.4 \%)$ were attending mainstream schools, ten $(47.6 \%)$ were attending special schools. All but one child diagnosed with childhood autism were attending special schools. A total of 19 children (90.5\%) were formally statemented for special educational needs and received additional support at school. Two children (9.5\%) - one child with Asperger's syndrome and one with semantic pragmatic language disorder - had not been statemented, but received additional support in the school setting.

The 2-year check had been carried out in all 19 children born in our area as part of the routine pre-school health surveillance. Two patients had moved into the area after two years of age. In both cases information on healthchecks was not available.

In a total of $12(63.2 \%)$ children abnormalities or concerns were documented at the 2-year-check. The most common area of concern was speech and language development (see table 3 ). In all children with childhood autism $(n=6)$ abnormalities were noted at this stage. In 7 $(36.8 \%)$ patients there were no concerns raised at this point.

The 3.5-year-check had been performed on 17 children. Concerns were documented in 16 cases $(94.1 \%)$. The main area of concern continued to be speech and language development ( 13 cases / $76.5 \%$ ), followed by concerns about behaviour ( 8 cases / $47.1 \%$ ). Only in one case - a child later diagnosed with Asperger's syndrome - there had been no concerns at that point (see table 4).

The mean age at the initial referral was 3.47 years (range $1.67-6.0$ years, median 3.42 , mode 3.5 years). The most common area of concern raised in the initial referral letter was speech and language development (18 cases / 85.7\%) followed by concerns about social interaction ( 10 cases / $47.6 \%$ ). Unusual behaviour was mentioned in 9 cases $(42.9 \%)$ at referral. This included obsessive, ritualistic, stereotypic behaviour, fixation on certain objects, resist- ance to change in routines and echolalia. Other concerns at referral were aggressive behaviour and short attention span (see table 5).

The next stage of the study was to assess the number of referrals which were made as a direct result of the routine checks. A total of 13 children (68.4\%) were referred for further specialist assessment as an outcome of the checks - 5 children $(26.3 \%)$ and 8 children $(42.1 \%)$ following the 2-year and 3.5-year checks respectively. In 6 cases $(31.6 \%)$ referrals were made unrelated to the routine checks. One child was referred before the 2-year check, 2 children were referred between the 2-year and 3.5-year checks and 3 children were referred sometime after the 3.5-year check.

\section{Discussion}

In this study we found the prevalence of PDD was at least 82.8 per 10.000 children which is even higher than previously reported. We consider this to be the minimum prevalence rather than the actual prevalence as a quarter of the schools did not respond. This relatively high prevalence may be accounted for by the fact that we concentrated on school-age children rather than on pre-school children like Chakrabarti and Fombonne [5], who reported a prevalence of 62.6 per 10.000. Fourteen children in our study population had been diagnosed before school entry, which would equal a prevalence of 55.2 per 10.000 at that point in time. However, it is noteworthy that the National Autistic Society (NAS) recently estimated the total prevalence of PDD to be 91 per 10,000 [10].

Observations of other authors support the impression that the incidence - and thereby also prevalence - of PDD has increased over the last decade [11-14]. Powell et al. [15] found that the incidence of autistic spectrum disorders in their population appeared to have increased by $55 \%$ per year over a five year period (1991-1996). The authors of this paper came to the conclusion that clinicians were becoming increasingly able and willing to make this diagnosis in pre-school children, rather than the data reflecting a "true" rise in number of cases. This theory has since been supported by a number of recent publications [14-16]. Interestingly, a recent epidemiolog- 
Table 3: Areas of concern documented at the $\mathbf{2}$ year check

\begin{tabular}{lc}
\hline Areas of concern at 2 yrs & Number of cases \\
\hline Speech and language development & $\mathrm{II}(57.9 \%)$ \\
Hearing & $\mathrm{I}(5.3 \%)$ \\
Motor development & $\mathrm{I}(5.3 \%)$ \\
Behaviour & $\mathrm{I}(5.3 \%)$ \\
None & $7(36.8 \%)$ \\
\hline
\end{tabular}

Table 3 shows the areas of concerns which were documented in the child health surveillance check at 2 years of age in children with PDD $(n=19)$. In two children there were two areas of concern noted. There was no data on 2 children who had moved into the area at a later point in life.

Table 4: Areas of concern documented at the 3.5 year check

\begin{tabular}{lc}
\hline Area of concern at $\mathbf{3 . 5}$ yrs & Number of cases \\
\hline Speech and language development & $13(76.5 \%)$ \\
Hearing & $1(5.9 \%)$ \\
Motor development & $1(5.9 \%)$ \\
Behaviour & $8(47.1 \%)$ \\
None & $1(5.9 \%)$ \\
\hline
\end{tabular}

Table 4 shows the areas of concerns which were documented in the child health surveillance check at 3.5 years of age in children with PDD $(n=17)$. In six children 2 areas of concern were documented. In four children no data concerning the check was available, in 2 cases because the child had moved into the area at a later point.

Table 5: Areas of concern raised in the initial referral letter

\begin{tabular}{lc}
\hline Area of concern at referral & Number of children \\
\hline Speech and language development & $18(85.7 \%)$ \\
Motor development & $2(9.5 \%)$ \\
Social interaction & $10(47.6 \%)$ \\
Unusual behaviour & $9(42.9 \%)$ \\
Aggressive behaviour & $2(9.5 \%)$ \\
Short attention span & $4(19.0 \%)$ \\
\hline
\end{tabular}

Table 5 shows the areas of concerns raised in the initial referral letter $(n=21)$. In some children there was more than one area of concern mentioned in the letter.

ical study in the U.K. has suggested that the incidence of PDD appears to have stabilised in the last few years [17].

In our study the prevalence of 23.7 per 10.000 for childhood autism was also higher than previously reported by other authors $[5,17,18]$. However, two recently published studies from groups in the United States have reported similar figures. Croen et al. reported a prevalence of 14.9 per 10.000 in Californian children [14], while the prevalence reported by Bertrand et al. in children from New Jersey was 40.0 per 10.000 [19].

Our prevalence for Asperger's syndrome (11.8 per 10.000) was lower than reported by Ehlers and Gillberg [20] (36 per 10.000), but higher than recently published by Chakrabati and Fombonne [5]. Again the explanation for the higher incidence of Asperger's syndrome in comparison to the latter group is likely to be due to the difference in age of our populations. Two of our three patients in this subgroup were only diagnosed after school entry.

The male preponderance we found in our study population of children with PDD was similar to observations published by other authors $[5,17,21,22]$.

It was reassuring to find that all children in our study were assessed and treated by the Speech and Language Therapy team and received additional support at school, with the majority $(90.5 \%)$ having been statemented for special educational needs. A tendency for improvements regarding statementing and special provisions at school for children with PDD has previously been reported by Smith et al. [23].

For a considerable proportion of children with PDD $(36.8 \%)$, no areas of concern were noted at the 2-year child health surveillance check. In contrast to this in nearly all cases of PDD (94.1\%) abnormalities had been noted at the 3.5-year check. Abnormal development had been documented in all cases of childhood autism at the 2-year check, but a significant amount of "milder" cases of PDD - including all 3 patients later diagnosed with Asperger's syndrome - had not been detected at that stage.

We found that at the 3.5-year check concerns about speech and language development had been raised in about $3 / 4$ of the PDD cases (vs. only $57.9 \%$ at 2 -year check) and that behavioural concerns were noted far more frequently ( $47.1 \%$ vs. $5.3 \%$ ). These results suggest that the 3.5-year check - and to a lesser extent the 2-year check is a valuable contributing factor in the early detection of PDD.

Another important finding was that $68.4 \%$ of the children with PDD were referred for further assessment as a direct result of the routine child health surveillance checks. This illustrates that abnormalities were not only noted and documented at the checks, but that action was taken in a large proportion of children to address these issues appropriately.

Recently the Joint Working Party on Child Health Surveillance (U.K.) has published a new edition of "Health For 
All Children" [24]. The authors of this document are proposing that no formal universal screening should be carried out at 2 years (i.e. $18-24$ months) and 3.5 years (i.e. 39-42 months). Instead they recommend a strategy whereby the health visitor negotiates the nature of subsequent reviews at the age of four months with the parents in the light of individual needs. However, at this age characteristic features of PDD would not have developed. This approach would rely mainly on the parents to recognise autistic features or abnormal development and subsequently seek assistance from health care professionals. Awareness training of play group and nursery staff as suggested by the National Initiative for Autism: Screening and Assessment (NIASA) may be an important tool to overcome this problem [25].

The guidelines that have been proposed by NIASA conclude that primary screening for PDD by the use of tests applied to the whole population at specific ages cannot be recommended, based on previous reports (e.g. by Baird et al. [26], who reported a low sensitivity of $38 \%$ for the CHAT / Checklist for Autism in Toddlers). However, the group of experts endorsed the recommendation that at specific times in the pre-school years (8-12 months, 2-3 years and 3-5 years) there should be a focus on development by a health professional with the parents or carer.

Early diagnosis of PDD is essential to facilitate early intervention. Various forms of intervention have been shown to be beneficial and improve overall outcome in non-randomised studies $[7,27,28]$. More recently, two small randomised controlled trials have demonstrated that early, intensive therapy can improve the intellectual development, language and visual-spatial skills of the affected child as well as significantly increase parent satisfaction $[29,30]$

The mainstays of therapy continue to be speech and language therapy and behavioural therapy. One approach is a TEACCH-based (Treatment and Education of Autistic and related Communication handicapped CHildren) home intervention programme, which has repeatedly been shown to be effective. Ozonoff and Cathcart [31] were able to demonstrate that children participating in this programme improved significantly more than the autistic children in the control group in the areas of fine motor, gross motor and non-verbal conceptual skills. Another promising approach is the NAS EarlyBird Programme. There is already supporting evidence of its efficacy, although long-term data requires further evaluation [8]. The early intensive behavioural intervention method (EIBI) is another behavioural approach which has been reported to be an effective intervention which may produce long-lasting and significant gains for young children with autism $[32,33]$. However, the assessment and evaluation of outcomes of interventions in complex disorders such as PDD is difficult and further studies are needed to evaluate the long-term impact of these methods.

We are aware of the limitations of this study, most notably that standardised assessment tools such as the widely used ADI (Autism Diagnostic Interview) were not employed in the initial diagnostic assessment. The diagnoses are based on assessments mainly conducted by experienced Consultants in Community Paediatrics, who are specifically trained for this role, but are observer dependent. This might have led to over-diagnosing or over-inclusion, especially at the "milder" end of the spectrum of PDD. The second major shortfall of this study was that we did not receive a response from all schools - which may have affected our prevalence. However, our epidemiological findings are consistent with observations reported by other authors, who have employed different methods to conduct their surveys.

\section{Conclusions}

The prevalences for PDD and the subcategories childhood autism and Asperger's syndrome we established in this study were similar to figures published recently, but much higher than reported a few years ago. Our data suggests that routine child health surveillance at 2 years and 3.5 years is a valuable contributing factor for the early detection of PDD, which ultimately facilitates early intervention. Thus, if routine surveillance ceases, then an appropriate alternative method of early detection should be put in place.

\section{Competing interests}

None declared.

\section{Authors' contributions}

MT drafted the manuscript. VN and MT reviewed the case files, collected the relevant data and carried out the statistical analysis. JR conceived of the study, and participated in its design and coordination. All authors read and approved the final manuscript.

\section{Acknowledgements}

The authors would like to thank all headteachers and Special Educational Needs Co-Ordinators within our region who have kindly contributed information for this study. We would also like to express our gratitude to Dr. Nellie Adjaye, Consultant Community Paediatrician at Maidstone Weald PCT, for all her advice and support. Finally, we would like to thank the staff of the public information section of the Kent County Council who have kindly provided valuable epidemiological data on the population of our district.

\section{References}

I. Makela A, Nuorti JP, Peltola H: Neurologic disorders after measles-mumps-rubella vaccination. Pediatrics 2002, I I 0(5):957-63. 
2. Madsen KM, Hviid A, Vestergaard $M$, Schendel D, Wohlfahrt J, Thorsen $\mathrm{P}$, Olsen J, Melbye M: A population-based study of measles, mumps and rubella vaccination and autism. $N$ Engl J Med 2002, 347( I 9): |477-82.

3. Taylor B, Miller E, Lingam R, Andrews N, Simmons A, Stowe J: Measles, mumps and rubella vaccination and bowel problems or developmental regression in children with autism: population study. BMJ 2002, 324(7334):393-6.

4. Lotter V: Epidemiology of autistic conditions in young children, I: prevalence. Soc Psych 1966, I: I 24- I37.

5. Chakrabarti S, Fombonne E: Pervasive developmental disorders in preschool children. JAMA 200I, 285(24):3093-3099.

6. Eikeseth S, Smith T, Jahr E, Eldevik S: Intensive behavioural treatment at school for 4- to 7-year-old children with autism. A Iyear comparison controlled study. Behav Modif 2002 26(I):49-68.

7. Stone WL, Yoder PJ: Predicting spoken language level in children with autism spectrum disorders. Autism 2001, 5(4):34|-36I.

8. Shields J: The NAS EarlyBird Programme: partnership with parents in early intervention. The National Autistic Society. Autism 200I, 5(I):49-56.

9. Gillberg IC, Gillberg C: Asperger syndrome - some epidemiological considerations: a research note. J Child Psychol Psychiatry 1989, 30(4):631-638.

10. Wing L, Potter D: Notes on the prevalence of autistic spectrum disorders. Paper originally published for the autism99 Internet conference 1999. Full free version available via the National Autistic Society website http://www.nas.org.uk or directly via http://w02021 I.web.dircon.net/pubs/archive/prevalence.html

II. Charman T: The prevalence of autism spectrum disorders. Recent evidence and future challenges. Eur Child Adolesc Psychiatry 2002, I I (6):249-56

12. Prior $M$ : Is there an increase in the prevalence of autism spectrum disorders? J Paediatr Child Health 2003, 39(2):8I-2.

13. Fombonne E: Epidemiological surveys of autism and other pervasive developmental disorders: an update. J Autism Dev Disord 2003, 33(4):365-82.

14. Croen LA, Grether JK, Hoogstrate J, Selvin S: The changing prevalence of autism in California. I Autism Dev Disord 2002 32(3):207-I5

15. Powell JE, Edwards A, Edwards M, Pandit BS, Sungum-Paliwal SR Whitehouse W: Changes in the incidence of childhood autism and other autistic spectrum disorders in preschool children from two areas of the West Midlands, UK. Dev Med Child Neurol 2000, 42(9):624-628.

16. Wing L, Potter D: The epidemiology of autistic spectrum disorders: is the prevalence rising? Ment Retard Dev Disabil Res Rev 2002, 8(3): $|5|-6 \mid$

17. Lingam R, Simmons A, Andrew N, Miller E, Stowe J, Taylor B: Prevalence of autism and parenterally reported triggers in north east London population. Arch Dis Child 2003, 88(8):666-70.

18. Bryson SE, Clark BS, Smith IM: First report of a Canadian epidemiological study of autistic syndromes. J Child Psychol Psychiatry 1988, 29(4):433-445.

19. Bertrand J, Mars A, Boyle C, Bove F, Yeargin-Allsop M, Decoufle P: Prevalence of autism in a United States population: the Brick Township, New Jersey, investigation. Pediatrics 200I, I 08(5): I | 55-6 |

20. Ehlers S, Gillberg C: The epidemiology of Asperger syndrome. A total population study. I Child Psychol Psychiatry 1993, 34(8): $1327-1350$.

21. Steffenburg S, Gillberg C: Autism and autistic-like conditions in Swedish rural and urban areas: a population study. $\mathrm{Br}$ Psychiatry 1986, I49:8I-87.

22. Fiona JS, Baron-Cohen S, Bolton P, Brayne C: Brief report: prevalence of autism spectrum conditions in children aged 5-II years in Cambridgeshire, UK. Autism 2002, 6(3):231-7.

23. Smith $B$, Chung MC, Vostanis $P$ : The path to care in autism: is it better now? J Autism Dev Disord 1994, 24(5):55 I-563.

24. Hall D, Elliman D, Editors: Health For All Children 4th edition. Oxford University Press; 2003.

25. NIASA - National Initiative for Autism: Screening and assessment. . Via NAS website http://www.nas.org.uk or http://w02021I.web.dircon.net/profess/niasa.html
26. Baird G, Charman T, Baron-Cohen S, Cox A, Swettenham J, Wheelwright $S$, Drew A: A screening instrument for autism at 18 months of age: A 6-year follow-up study. J Am Acad Child Adolesc Psychiatry 2000, 39(6):694-702.

27. Rogers SJ: Brief report: early intervention in autism. J Autism Dev Disord 1996, 26(2):243-246.

28. Smith T, Eikeseth S, Klevstrand M, Lovaas OL: Intensive behavioural treatment for preschoolers with severe mental retardation and pervasive developmental disorder. Am J Ment Retard 1997, I 02(3):238-49.

29. Jocelyn LJ, Casiro OG, Beattie D, Bow J, Kneisz J: Treatment of children with autism: a randomized controlled trial to evaluate a caregiver-based intervention program in community day-care centers. J Dev Behav Pediatr 1998, I 9(5):326-34.

30. Smith T, Groen AD, Wynn JW: Randomised trial of intensive early intervention for children with pervasive developmental disorder. Am J Ment Retard 2000, I 05(4):269-85.

31. Ozonoff S, Cathcart K: Effectiveness of a home program intervention for young children with autism. J Autism Dev Disord 1998, 28(I):25-32.

32. Lovaas Ol: Behavioural treatment and normal educational and intellectual functioning in young autistic children. J Consult Clin Psychol 1987, 55(1):3-9.

33. McEachin JJ, Smith T, Lovaas OI: Long-term outcome for children with autism who received early intensive behavioural treatment. Am J Ment Retard 1993, 97(4):359-72.

\section{Pre-publication history}

The pre-publication history for this paper can be accessed here:

http://www.biomedcentral.com/1471-2431/4/4/prepub

Publish with BioMed Central and every scientist can read your work free of charge

"BioMed Central will be the most significant development for disseminating the results of biomedical research in our lifetime. "

Sir Paul Nurse, Cancer Research UK

Your research papers will be:

- available free of charge to the entire biomedical community

- peer reviewed and published immediately upon acceptance

- cited in PubMed and archived on PubMed Central

- yours - you keep the copyright 